\title{
Perancangan Sistem Informasi Kelengkapan Pengisian Resume Medis Rawat Jalan di Rumah Sakit
}

\author{
Nurafni Hanifah*, Sabila Aulia Reihan, Yuda Syahidin, Meira Hidayati \\ Program Studi Informatika Rekam Medis, \\ Politeknik Piksi Ganesha Bandung, \\ Jawa Barat, INDONESIA \\ nhanifah@piksi.ac.id*, sarehan@piksi.ac.id
}

\begin{abstract}
Hospital is an establishment that's engaged within the field of health service institutions that provide perfect health services for every individual who organizes outpatient, inpatient, and emergency services. By providing health services, hospitals must have complete data from patients in order that services get optimal results. At the time of service, the medical history department is that the most vital role. additionally, to provide services together with it, the medical history section also processes historical data from the patient. This medical record consists of registration, filling inpatient data, processing, data analysis, and documentation. If the medical record sheet is filled out completely and properly, the health history is going to be said to be appropriate and good. the tactic administered through chemical analysis resulted in the conclusion that the outpatient medical resume form in 2019 at the Bandung Hospital was found to possess an incomplete authentication review. The hospital must improve improvements in filling out the medical resume form for authentication that has got to be filled out completely because this authentication is proof that the doctor has done treatment for his patient.
\end{abstract}

Keywords: Completeness of Medical Resume; Hospital; Outpatient.

ABSTRAK - Rumah Sakit adalah suatu lembaga yang bergerak di bidang institusi pelayanan kesehatan yang memberikan pelayanan kesehatan setiap individu dengan sempurna yang menyelenggarakan layanan rawat jalan, rawat inap serta gawat darurat. Dengan menyelenggarakan pelayanan kesehatan rumah sakit harus memiliki kelengkapan data dari pasien agar pelayanan mendapatkan hasil yang optimal. Pada saat pelayanan bagian rekam medis adalah yang paling berperan penting. Selain memberi pelayanan bersama dengan itu juga bagian rekam medis mengolah data-data riwayat dari pasien tersebut. Riwayat kesehatan ini terdiri dari pendaftaran, pengisian data pasien, pengolahan, analisis data dan dokumentasi. Jika lembar riwayat kesehatan diisi secara lengkap dan benar maka pengisian riwayat kesehatan akan dikatakan sesuai dan baik. Metode yang dilakukan melalui analisis kualitatif menghasilkan kesimpulan bahwa formulir resume medis pasien rawat jalan ditahun 2019 di Rumah Sakit Bandung ditemukan review autentikasi yang belum lengkap. Pihak RS harus meningkatkan perbaikan dalam pengisisan form resume medis untuk autentikasi wajib diisi dengan lengkap sebab autentikasi ini merupakan bukti bahwa dokter telah melakukan pengobatan untuk pasiennya.

Kata Kunci: Kelengkapan Resume Medis; Rumah Sakit; Rawat Jalan.

\section{Pendahuluan}

Di era teknologi sekarang layanan kesehatan yang diinginkan oleh masyarakat dapat dipilih sesuai dengan kebutuhan yang dapat diterima. Rumah sakit selalu siap untuk memberikan pelayanan yang profesional dan sudah tidak perlu diragukan lagi oleh pengguna jasa kesehatan. Masih banyak fasilitas pelayanan didunia kesehatan yang hanya menyediakan data lama, sehingga dimasa yang akan datang untuk memberi pelayanan yang lebih baik pada pasien dibutuhkan data yang dapat memprediksinya [1].

Pelayanan dunia kesehatan di Klinik, rumah sehat ataupun rumah sakit dimasa ini sangat dibutuhkan masyarakat. Kesehatan suatu makhluk hidup seperti manusia berbeda-beda, tidak akan ada manusia yang sehat secara terus menerus [2]. Kesehatan yang menurun membuat kita memerlukan fasilitas kesehatan. Saat mendaftarkan layanan kesehatan, setiap pasien yang mendaftar maka akan memiliki riwayat kesehatannya sendiri di Rumah sakit atau fasilitas kesehatan tersebut.

Dengan menyelenggarakan pelayanan kesehatan, rumah sakit harus memiliki kelengkapan data dari pasien agar pelayanan mendapatkan hasil yang optimal. Pada saat pelayanan, bagian rekam medis adalah yang paling berperan penting. Karena selain memberi pelayanan, bersama dengan itu bagian rekam medis juga mengolah data-data dari pasien tersebut [1]. Masyarakat secara keseluruhan pasti tahu apa itu riwayat medis atauyang disingkat dengan RM. Riwayat medis atau riwayat kesehatan dari seorang pasien dapat meliputi beberapa hal, identitas dari pasien merupakan gambaran umum dari riwayat medis tentunya karena merupakan pengenal mengenai riwayat kesehatan yang telah diberikan oleh 
tenaga kesehatan seperti dokter kepada pasien tersebut [3]. Saat memberikan pelayanan, pencatatan dokumen harus dinyatakan sesuai dengan kronologi, akurat dan tentunya sistematis. Selain itu, dokter juga harus mencantumkan namanya, waktu saat memberikan pelayanan dan juga tanda tangan sebagai bukti sah bahwa dokter tersebut yang memberikan pelayanan.

Publik harus tahu bahwa praktik yang baik akan menyimpan seluruh riwayat medis. Rekam medis khususnya di Indonesia memiliki peraturan - peraturan yang tertuang diUndang-Undang Nomor 44 Tahun 2009 tentang Rumah Sakit, Undang-Undang Nomor 29 Tahun 2004 tentang Praktik dan tertuang dalam Peraturan Menteri Kesehatan Nomor 269/ MENKES/ PER/ III/ 2008 tentang Rekam Medis, dan juga untuk pelaksanaannya tercantum dalam Pasal 47 ayat (3) Undang-Undang Nomor 29 Tahun 2004 mengenai Praktek.

Untuk melengkapi rekam medis yang masih manual yakni menggunakan kertas, beberapa rumah sakit yang ada didunia, mulai menerapkan Rekam medis berbasis elektronik termasuk Negara Indonesia. Karena Rekam Medis Elektronik ini bisa disebut center atau nyali data sebuah Rumah sakit mengenai sistem datanya. Meskipun RME diatur dalam Permenkes No. 269/ Menkes/ PER/ III/ 2008, hal itu tetap membuat Rekam Medis Elektronik ini menjadi hal yang sedikit dilema bagi Rumah sakit. Tetapi dalam UU ITE nomor 19 Tahun 2016, hal ini memberikan rumah sakit kemudahan untuk menerapkan sistem Rekam Medis Elektronik.

Perkembangan sistem riwayat kesehatan elektronik di Rumah Sakit Bandung saat ini masih dilaksanakan bertahap karena harus terintegrasi dengan data system rumah sakit. Untuk saat ini paper based masih digunakan di Instalasi Rekam Medis Rumah Sakit Bandung. Karena banyaknya client atau pasien yang membutuhkan sebagai bahan, alat dan bukti untuk menegakan keadilan dalam sejarah kedokteran dimata hukum [4].

Dengan harapan ke depan rekam medis memiliki aturan tentang RME dan dapat menjalankan rekam medis elektronik secara sah sehingga dapat dimanfaatkan sebagai bukti di pengadilan.

Hasil dari permasalahan penelitian yang didukung latar belakang diatas adalah Bagaimana sistem pengetahuan kelengkapan pengisian lembar resume medik pasien rawat jalan di RS Kota Bandung.

Penelitian ini memiliki tujuan untuk meneliti implementasi sistem data formulir riwayat kesehatan rawat jalan RS Kota Bandung secara keseluruhan, menganalisis kekurangan-kekurangan yang terjadi pada sistem data pengisian lembar riwayat kesehatan rawat jalan di RS Kota Bandung [5], merancang sistem data terkomputerisasi untuk melengkapi bentuk riwayat medis rawat jalan di RS Kota Bandung, mengetahui cara merancang sistem program yang dapat dibuat selama program komputerisasi.

Manfaat penelitian ini untuk mempelajari dan mengembangkan ilmu pengetahuan yang telah dimengerti dan mampu diterapkan di dunia kerja nanti, untuk menambah wawasan bagi lembaga yang berkaitan dengan ilmu rekam medis elektronik mengenai sistem informasi kelengkapan pengisian resume medis.

\section{Metodologi}

Metode riset secara kualitatif sering digunakan oleh penulis untuk menyelesaikan penelitian. Karena melihat kondisi di lapangan tentang analisis kelengkapan ini memberikan gambaran bagi penulis sehingga dapat digunakan untuk merancang suatu sistem data kelengkapan resume medis [4]. Sugiyono berpendapat bahwa "suatu penelitian yang dapat dipahami dari sisi pastisipan dilihat dari kondisi social dan situasi objek penelitian akan lebih pas menggunakan penelitian kualitatif' [6].

\section{A. Teknik Pengumpulan Data}

Pengumpulan data pada penelitian ini menggunakan wawancara, observasi, dan studi kepustakaan. Wawancara merupakan Metode komunikasi secara verbal, untuk mendapatkan fakta-fakta dan informasi yang dibutuhkan oleh peneliti sehingga dapat mewujudkan tujuan penelitian [7]. Dalam penelitian ini, wawancara dilakukan secara langsung kepada petugas rekam medis di rumah sakit sehingga penulis dapat mendapatkan beberapa informasi yang akurat mengenai resume medis pasien. Sementara observasi merupakan teknik yang biasa dilakukan untuk mengumpulkan data penelitian dengan mengamati secara langsung kelapangan [8]. Penelitian ini dilakukan dengan metode observasi partisipasi, dengan berpartisipasi secara langsung kesektor lapangan yakni bagian instalasi rekam medis di Rumah sakit kota Bandung. Pada penelitian ini dilakukan pengamatan dan ikut melakukan kegiatan rekam medis setiap harinya selama 2 bulan di Rumah sakit tersebut. Sehingga penulis mendapatkan gambaran yang lebih nyata dan rinci untuk mendapatkan informasi, pengetahuan dan permasalahan yang sesuai untuk dijadikan bahan penelitian. Dan pada tahap studi kepustakaan dalam penelitian ini dilakukan pengumpulan data dan mencari referensi dari beberapa sumber, seperti membaca beberapa buku dan artikel ilmiah yang berkaitan langsung dengan masalah penelitian, sehingga mendukung dalam perancangan dan penulisan laporan [2].

\section{B. Metode Perancangan Sistem}

Metode yang digunakan dalam penelitian ini adalah metode waterfall. Metode ini dipilih karena metode ini dikelola dengan pendekatan saintifik mulai dari tahap kebutuhan sistem kemudian pindah ke tahap selanjutnya seperti analisis, desain, coding, verification, dan maintanance.

\section{Hasil dan Pembahasan}

\section{A. Hasil Analisis}

Alur pengisian formulir resume medis rawat jalan yang sedang dirancang secara lengkap menggunakan pemograman Visual Studio 2010. Hasilnya pada form resume medis rawat jalan 2019 di Rumah Sakit Bandung untuk ketidaklengkapan yang terdapat pada form identitas 
pasien seperti tanggal lahir, umur, jenis kelamin, dan alamat. Ketidaklengkapan dalam autentikasi terdapat pada nama dokter, tanggal pengisian pengobatan pasien, nama jelas dokter, dan tanda tangan dokter [?].

\section{B. Sistem yang akan Berjalan}

Sistem yang akan dirancang pada penelitian ini terdiri dari Flowmap, Diagram Context, Data Flow Diagram (DFD), Entity Relationship Diagram (ERD).

Gambar 1 merupakan Flowmap sistem yang sedang dirancang. Gabungan dari flowchart merupakan bagan yang menunjukan arus pekerjaan secara keseluruhan dari sistem [10].

Gambar 2 merupakan Diagram Context merupakan tingkatan paling tinggi didalam diagram aliran data yang hanya memuat satu proses, memperlihatkan sistem secara menyeluruh. Semua entitas eksternal pada diagram konteks berbentuk aliran-aliran data utama menuju dan dari sistem.

Gambar 3 merupakan Data Flow Diagram (DFD) pada tahap ini penggunaan notasi sangat membantu didalam komunikasi dengan memakai sistem untuk memahami sistem secara logika. Penggunaan DFD Level 0 hanya menggambarkan sistem secara basik saja berfungsi untuk menjelaskan aliran data dari input sampai output [10].

Gambar 4 merupakan Entity Relationship Diagram (ERD) merupakan suatu komponen himpunan entitas dan relasi yang dilengkapi dengan atribut serta menemukan fakta dari dunia nyata yang diteliti, menggambarkan data yang diteliti dan hubungan antara data secara global dengan menggunakan ERD.

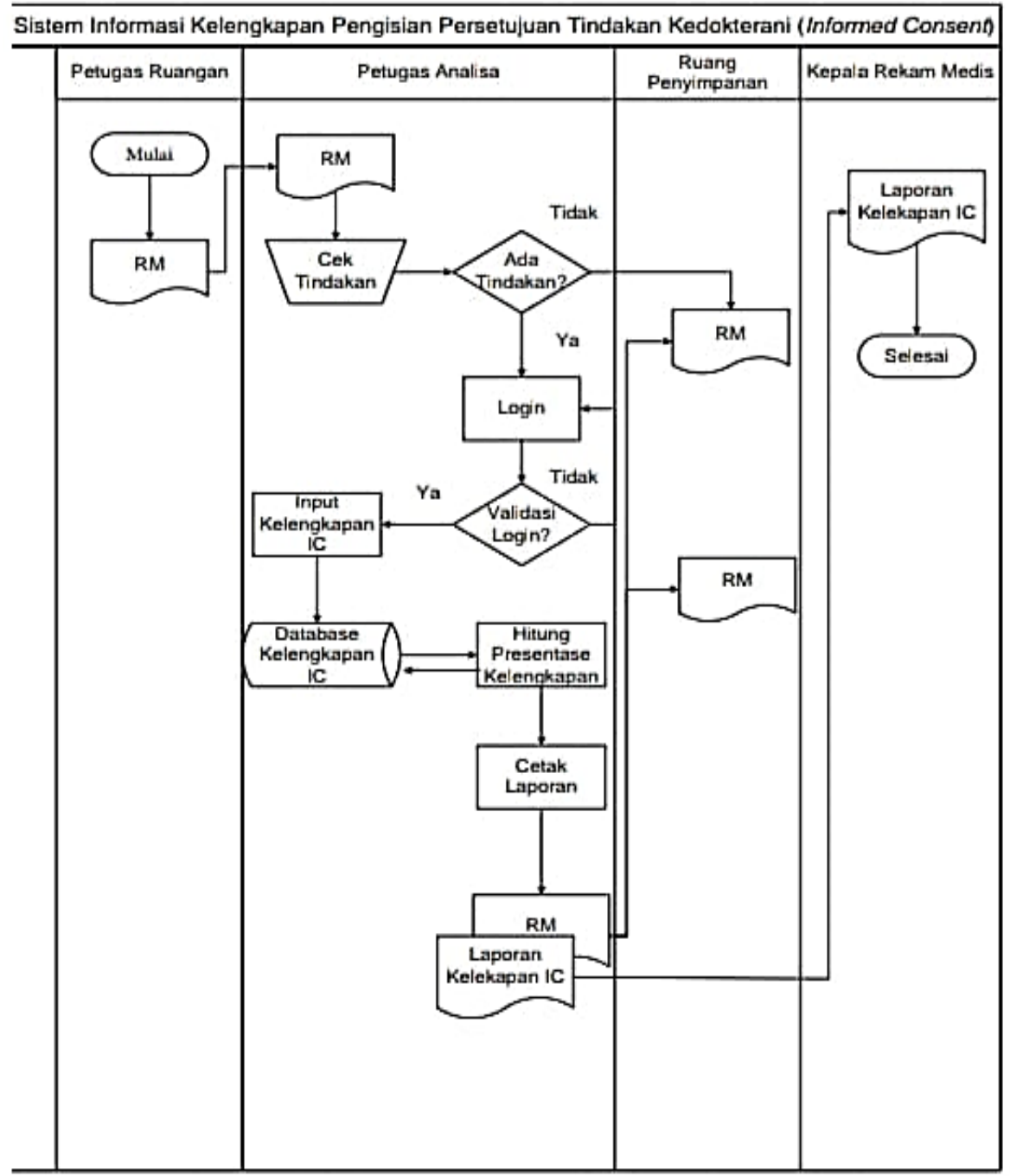

Gambar 1. Flow map Rancangan Sistem 


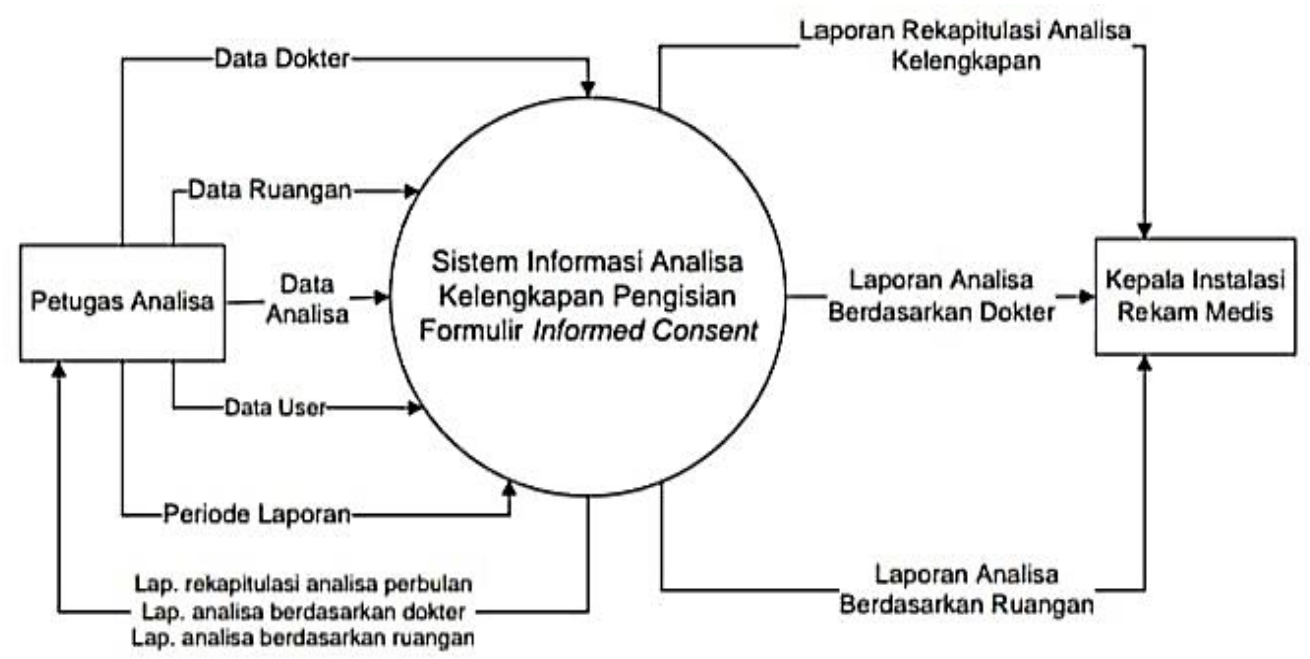

Gambar 2. Diagram Context Rancangan Sistem

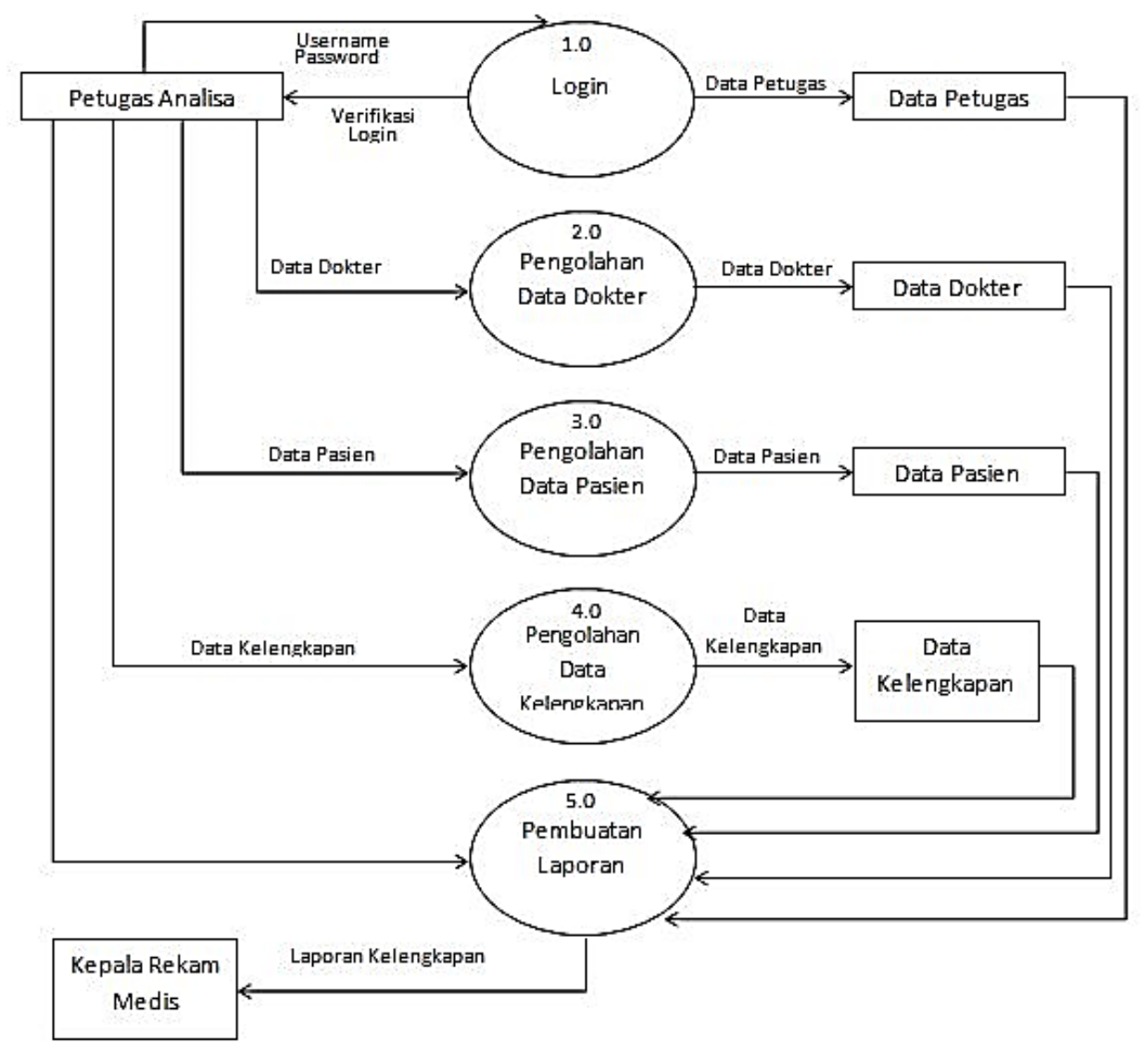

Gambar 3. Data Flow Diagram (DFD) Level 0 Rancangan Sistem 


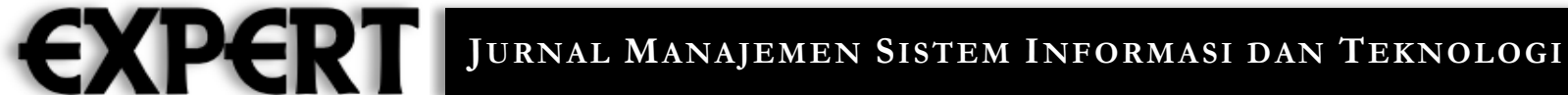

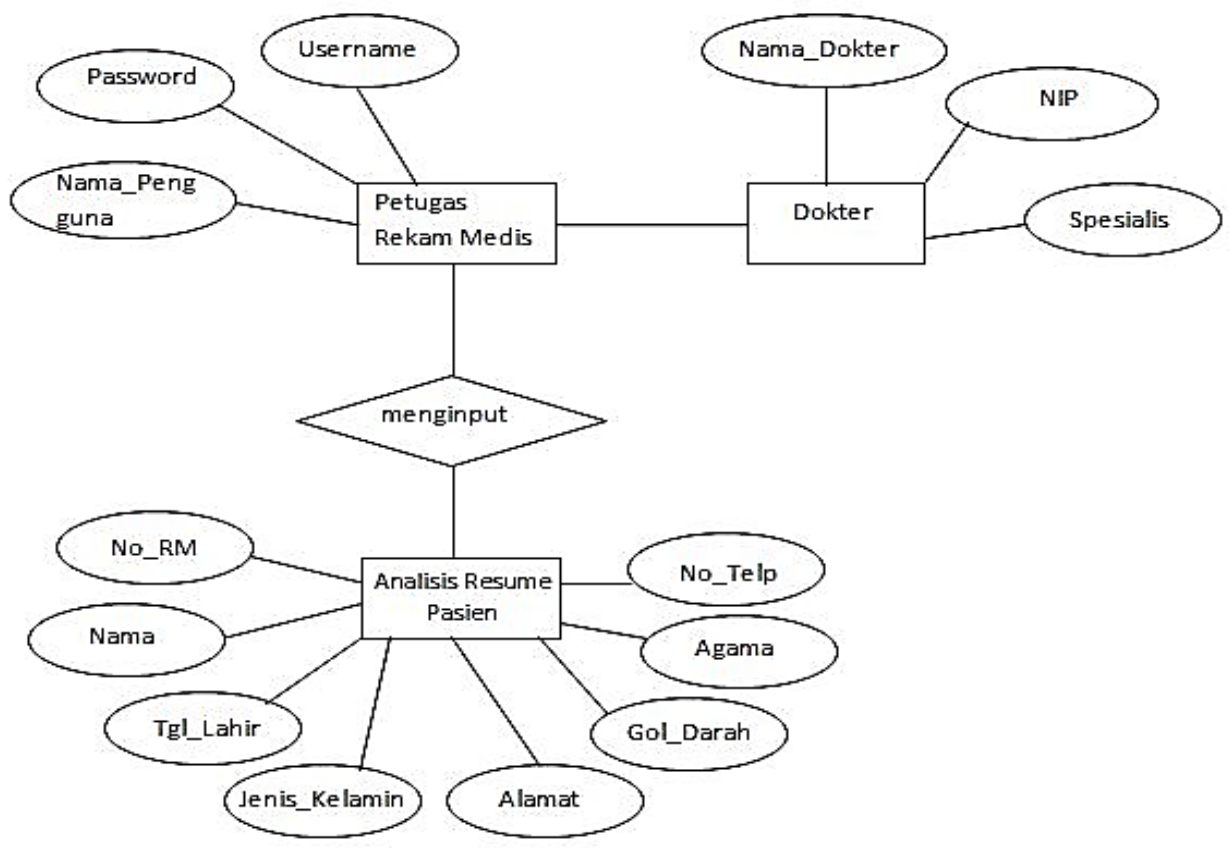

Gambar 4. Entity Relationship Diagram (ERD) Rancangan Sistem

\section{Implementasi Sistem}

Gambar 5 merupakan tampilan awal masuk kedalam menu utama yang terdiri dari Username dan Password setelah itu klik OK.

Gambar 6 merupakan tampilan menu Input User merupakan tampilan menu utama yang terdiri Username, Password, Nama Pengguna. Tampilan menu User diisi oleh petugas rekam medis, untuk mencari identitas pasien yang akan menjalani pengobatan di RS Kota Bandung.

Gambar 7 merupakan tampilan menu Input Dokter merupakan tampilan menu berisikan identitas dokter yang terdiri dari Nama Dokter, NIP, Spesialis. Tampilan menu Input Dokter diisi oleh petugas Rekam Medis sesuai dengan data yang diberikan oleh Dokter.

Gambar 8 merupakan tampilan menu analisis yang merupakan tampilan yang berisikan tentang identitas pasien secara lengkap terdiri dari No. RM, Nama Dokter, Poliklinik, No. BPJS, Nama, Tanggal Lahir, Jenis Kelamin, Alamat, Gol darah, Agama, No. Telp, Tanggal Analisis. Tampilan menu analisis ini diisi oleh petugas Rekam Medis.

Gambar 9 merupakan tampilan menu laporan yang berisi tentang hasil laporan berobat di RS Kota Bandung, bisa ditemukan sesuai tanggal terakhir pasien berobat. Terdiri dari Tanggal, Bulan, dan Tahun.

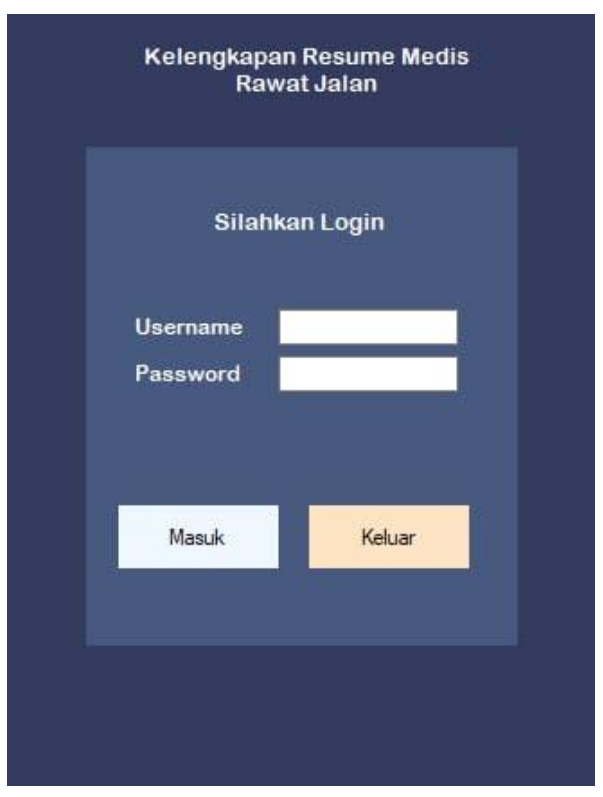

Gambar 5. Form Login Sistem 


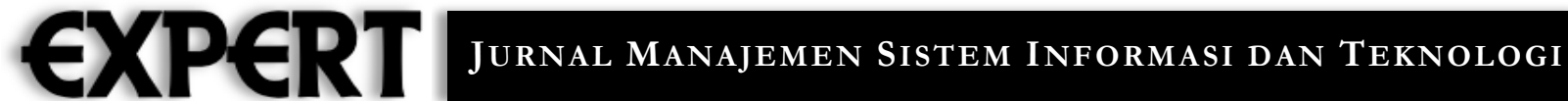

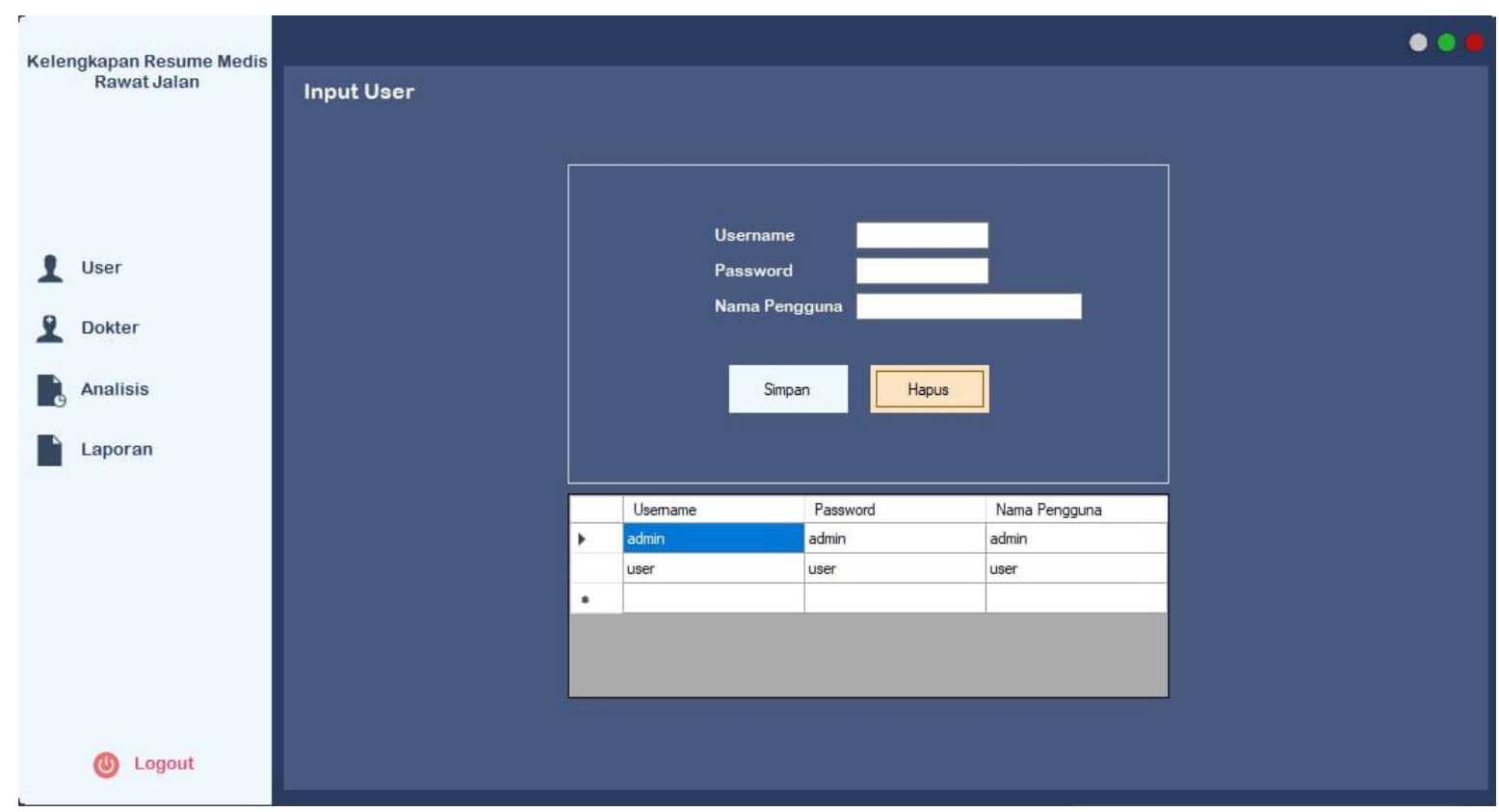

Gambar 6. Form Input User

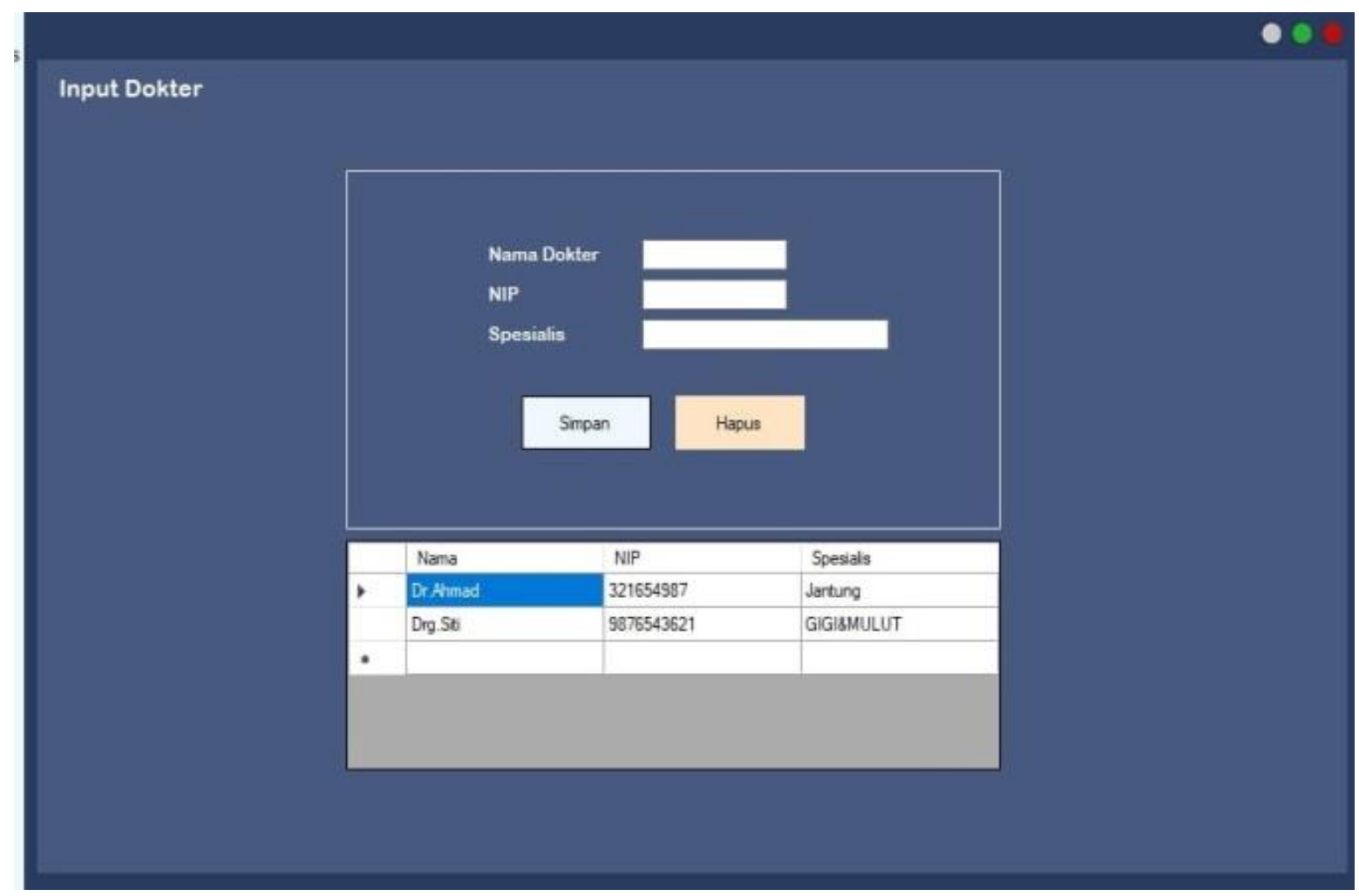

Gambar 7. Form Input Dokter 


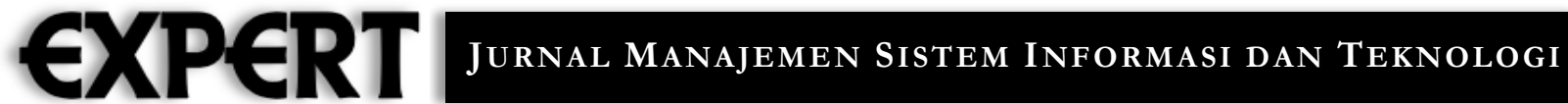

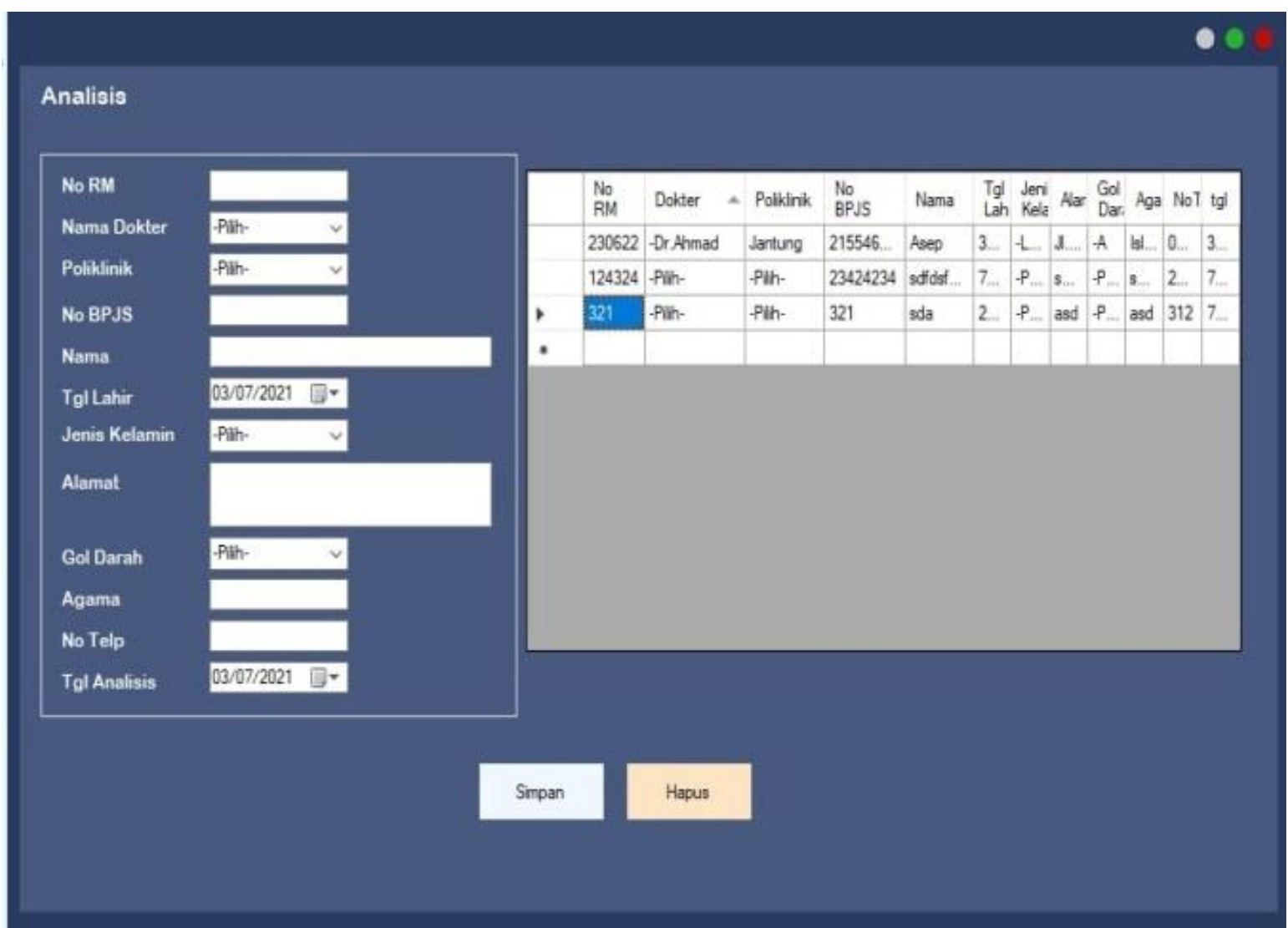

Gambar 8. Form Analisis

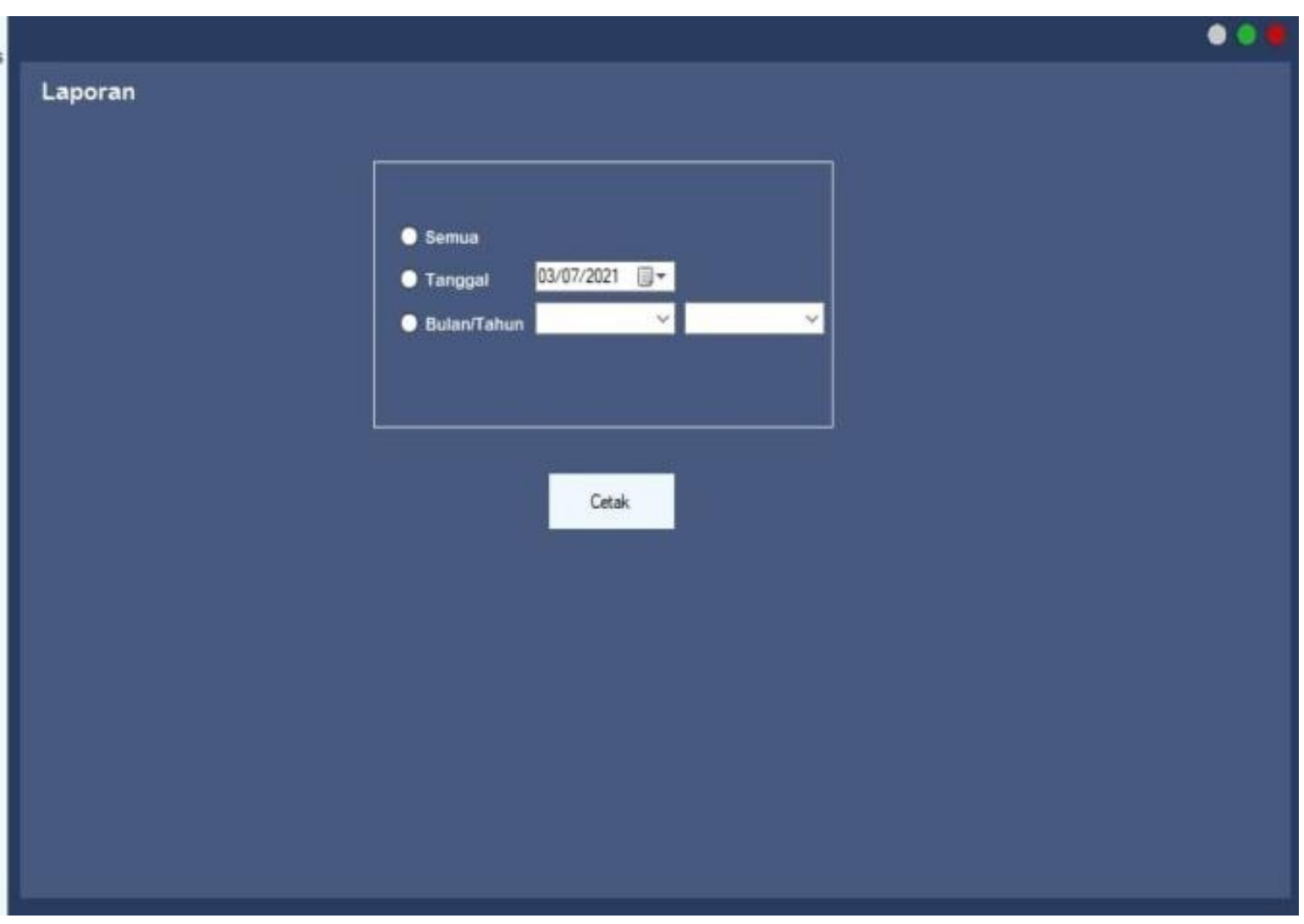

Gambar 9. Form Laporan 


\section{Kesimpulan}

Melalui penelitian analisis kualitatif menghasilkan kesimpulan bahwa formulir resume medis pasien rawat jalan ditahun 2019 di Rumah Sakit Bandung ditemukan 2 (dua) review yaitu identitas pasien, review autentikasi yang benar tetapi tidak sesuai dengan Permenkes No 269/ Menkes/ PER/ III/ 2008. Pihak RS harus meningkatkan dalam pengisian form resume medis, dalam melengkapi identitas harus ada surat keputusan yang sah dan akurat tentang identitas pada formulir tersebut agar ada keseragaman dalam pengisian identitas. Untuk autentikasi wajib diisi dengan lengkap karena autentikasi ini merupakan bukti bahwa dokter telah melakukan pengobatan untuk pasiennya, dalam pencatatan yang benar perlu dilakukan perbaikan. Maka dengan dirancangnya sistem ini diharapkan dapat membantu dalam pengisian kelengkapan resume medis di RS Bandung.

\section{Daftar Pustaka}

[1] E. P. D. Patria, "Resume Medis Rawat Inap Di Rsud Meuraxa," vol. 3, no. 1, pp. 1-12, 2019.

[2] D. Sundani, "Kualitas Sistem Informasi Pencatatan dan Pelaporan Kejadian Ikutan Pasca Imunisasi," vol. 8, no. 200, pp. 35-41, 2022.

[3] Y. Syahidin et al., "Perancangan Sistem Informasi Pasien Appointment," vol. XVIII, pp. 338-342, 2019
[4] N. Luh, P. Devhy, A. Agung, and G. Oka, "Analisis Kelengkapan Rekam Medis Rawat Inap Rumah Sakit Ganesha di Kota Gianyar Tahun 2019". Rekam Medis dan Informasi Kesehatan STIKES Wira Medika Bali. vol. 2, no. 2, 2019.

[5] S. Sugiyanto, W. Widodo, W. Warijan, and R. Isnaeni, "Analisis Kuantitatif Kelengkapan Pengisian Formulir Resume Medis Pasien Rawat Inap Tahun 2015 Di RSUD R.A Kartini Jepara," J. Rekam Medis dan Inf. Kesehat., vol. 1, no. 1, p. 1, 2018, doi: 10.31983/jrmik.v1i1.3572.

[6] Sugiyono, Metode Penelitian Kuantitatif, Kualitatif dan R\&D, 2nd ed. Bandung: CV Alfabeta, 2009.

[7] R. Agustiani, "Sistem Informasi Pelayanan Kesehatan Pasien Rawat Inap pada Rumah Bersalin Xaverius Tanjung Karang Bandar Lampung," Expert J. Manaj. Sist. Inf. dan Teknol., pp. 37-45.

[8] R. Widia, V. Novianti, Y. Syahidin, and M. Hidayati, "Sistem Informasi Korespondensi Rekam Medis di Rumah Sakit Menggunakan Microsoft Visual Studio," Expert J. Manaj. Sist. Inf. dan Teknol., vol. 8, no. 200, pp. 56-63, 2022.

[9] Y. Yanuar, "Perancangan Sistem Informasi Kelengkapan Pengisian Formulir Informed Consent di RS Al Islam Bandung," J. E-Komtek, no. 1, pp. 1-20, 2018, doi: 10.31227/osf.io/v54gm.

[10] J. Hartono, Pengenalan Komputer: Dasar Ilmu Komputer, Pemrograman, Sistem Informasi dan Intelegensi Buatan., 3rd ed. Yogyakarta: Andi Offset, 2002. 